\title{
GENDER AND THE HIDDEN LIFE OF INSTITUTIONS
}

\section{Pre-publication version submitted to Public Administration for publication in vol 91, no 3, pp 599-615.}

\section{LOUISE CHAPPELL AND GEORGINA WAYLEN}

New Institutionalism has shown that the 'rules of the game' are crucial to structuring political life in terms of constraining and enabling political actors and influencing political outcomes. A limitation of this approach however has been its overemphasis on formal rules, with much less attention paid to how informal rules work alongside and in conjunction with formal institutions to shape actors and outcomes. This article contributes to an emerging literature that highlights the importance of informal institutions by bringing into focus one element that has been hidden in these debates - the influence of gender norms and practices on the operation and interaction between formal and informal institutions. It highlights some of the key benefits of a gender analysis for understanding political institutions in both their formal and informal guise and considers some of the challenges in building a research agenda that requires new methods and techniques of inquiry.

\section{INTRODUCTION}

Improving our understanding of institutions - what they are and how they operate - has long been a key task facing many social scientists. New Institutionalism (which currently includes at least four variants - rational choice, historical, sociological and discursive institutionalism) has led this very broad field since the 1980s (March and Olsen 1984; North 1990; Hall and Taylor 1996; Thelen 1999; Rhodes et al 2006; Schmidt 2008). Most scholars now agree that institutions are the 'rules of the game' - the rules, norms and practices - that structure political, social and economic life, even if each variant of New Institutionalism (NI) differs in its explanations of institutional creation, structure and agency, and power (Mahoney and Thelen 2010). Although remarkable strides have been made in institutional analysis, much remains to be done, for example in understanding not just institutional continuity but also institutional change. One lacuna in many accounts is any understanding of institutions as gendered and how this impacts on their design, evolution and outcomes. Indeed although NI, and especially its historical variant, may have been attuned to the ways in which institutions distribute power unevenly between groups (Hall and Taylor 1996, p. 941), no attention has been given to the gender dimension of this. This deficiency detracts from the explanatory power of NI. However, scholars participating in the 'institutional turn' within gender scholarship are now rectifying this problem (Mackay and Waylen 2009; Krook and Mackay 2011). A broadly defined 'feminist institutionalism' (FI) has explicitly critiqued existing institutionalisms as well as utilized tools of gender and of institutional analysis (most commonly influenced by historical institutionalism) to improve our understanding of institutional design, processes and change.

This paper engages with this new gendered approach to institutions but seeks to 
add to it, and to the NI literature more generally, by emphasizing the often 'hidden' aspects of political institutions - in particular, the informal aspects of executive, legislative, bureaucratic, legal and constitutional arenas - to highlight the influence informal rules and practices have on institutional design and outcomes. While informal rules and norms have long been identified in NI as central to institutional processes and outcomes, Mackay et al (2010, p. 576) are correct in pointing out that 'both the specific influence of informal institutions and the interplay between formal and informal institutions are often under-theorized and underplayed in empirical studies' in both gendered and non-gendered institutionalist analysis in political science. Therefore by bringing into focus informal rules and practices, and how they are gendered, this paper does three things: it contributes to the NI literature a more nuanced understanding of institutions, for example through the introduction of concepts such as gender regime. Second by overtly recognizing the formal and informal and their interaction, it also contributes to the development of FI; and finally it improves both FI's and NI's understandings of why the introduction of new formal rules do not always result in the outcomes intended and desired by institutional designers in different contexts. Adding a gender power dimension to NI not only reveals who has the power to make institutional design decisions but also why some unexpected outcomes occur and why some reforms are more difficult to achieve than others.

To fulfill these tasks, this article answers a number of questions. The first section addresses the question of what is gender and why is it necessary to take a gendered approach to institutions? The second part of the article asks what is the relationship between gender and formal and informal institutions? It also explores what a focus on gender will add to an understanding of the hidden life of institutions. Finally, the last section considers how we might operationalize a gendered approach to formal and especially informal rules and practices through a case study of civil service recruitment to the United Kingdom (UK) core executive, before exploring the wider implications for a new research agenda. Addressing all these questions is not an easy task. Informal rules and practices are notoriously difficult to unravel and research. This is particularly the case in relation to the gender dimensions of such rules because these are often the status $q u o$; they are the unquestioned ways of operating seen as natural and immutable, if participants are even aware of them. But it is also because some of the research methods needed to uncover the links between formal and informal rules and gender are not always ones political scientists are comfortable with and can present difficulties of access and confidentiality. As Radnitz notes, studying informal institutions 'requires political scientists to travel outside of their "comfort zone," and to adopt the working assumptions, theoretical approaches, and methodologies of fields such as sociology and anthropology' (2011, p. 352).

\section{UNDERSTANDING GENDER}

What does the term gender mean in relation to political institutions? How is it manifested through institutions? What does it contribute to an understanding of institutional power? According to Beckwith, gender emerges: 
from stereotypes about male and female behavior; from characteristics and behaviors conventionally associated with women and men; from normative assumptions about appropriate behaviors of men and women; from assumptions about biological difference; and from social structures of power and difference (2010, p. 160).

Gender can be seen to operate within institutions in two senses: nominally and substantively. The nominal dimension, or what Goetz (2007) defines as 'gender capture', results from men's historical and ongoing dominance of positions of power in political organizations in greater numbers than women (Witz and Savage 1992). Over time women have challenged male dominance by entering the state in large numbers. The mere presence of women in institutional spaces has been disruptive because they have drawn attention to the extent of male control and revealed some of hidden expectations that exist within these spaces (Lovenduski 2005, p. 147). However, even if women reached parity with men in all political, legal and bureaucratic positions, there is no guarantee that institutions would operate differently. As Hooper (2001, p. 52) notes, 'swapping female for male bodies in traditionally masculine arenas does little to disrupt either the symbolism or practices of the gender order'; because of the operation of more deeply embedded substantive gender dimensions (Savage and Witz 1992), or a gender 'bias' that 'seep[s] into supposedly impartial or gender neutral arrangements' (Goetz 2007, p. 47) of political institutions. Lovenduski provides a vivid example of how this gender bias operates in the UK Parliament (and more so than in many institutions):

Requirements for masculine dress codes, provision for hanging up one's sword but not for looking after one's child, admiration for demagoguery and conflict, adversarial styles of debate, a chamber whose acoustics favour loud voices, the frequent use of military metaphors, the regularly reported experience of women MP's barred by staff from 'Member only' areas are all manifestations of the gender regime of the UK parliament (2005, p. 147).

Gender bias emerges from a set of social norms founded on accepted ideas about femininity and masculinity. These norms are usually (but not ineluctably) linked to a particular sex: the former are assigned to women and the latter to men. Masculinity is associated with 'positive' qualities including 'rationality, autonomy, prudence, strength, power, logic, boundary setting, control, and competitiveness' (Hooper 2001, p. 44) whereas femininity is its binary opposite, associated with passivity, nature, care, emotion and irrationality. Both masculinity and femininity come in plural forms, taking on different hues depending upon the particular institutional setting, and of course, intersecting with other dimensions such as race, class and sexuality. Across state institutions we find various forms of femininity and masculinity at work, with some forms of the latter operating hegemonically. Connell highlights examples of hegemonic masculinity in 'the physical aggression of front line troops or police, the authoritative masculinity of commanders and the calculative rationality of bureaucrats' (1987, pp.1289). While femininity is expressed differently - the caring nurse, the compliant secretary, 
the 'bossy' headmistress - it is always subordinate to the prevailing hegemonic masculinity. Nevertheless, feminine norms are still powerful in shaping institutional settings. Feminine traits provide the 'other' without which masculinities could not be defined (Lovenduski 2005, p. 51; Duerst-Lahti 2008, p.179). Masculinity (and its associated norms) reflects what is valued, while femininity operates 'a residual category, a foil or Other for masculinity to define itself against' (Hooper 2001, p. 43).

As social constructions, gender norms do not determine that women will act in a feminine way or men the reverse. However, political actors, traditionally men, have acted as if sex and gender are mapped on to each other, leading to the establishment of a 'gendered logic of appropriateness' within institutional arenas (Chappell 2006). This logic prescribes (as well as proscribes) 'acceptable' masculine and feminine forms of behaviour, rules and values for men and women within institutions. Men, operating within a hegemonic normative code, have been thought to possess the appropriate skills, knowledge and temperament to design and maintain the institutions of the state, while most women - assumed to be irrational, fragile and dependant - have tended to be relegated to supporting roles as low grade clerks, cleaners, tea ladies, and wives - but again located differently according to their racial and class positions (Lovenduski 2005, p. 147).

The institutional dominance of particular forms of masculinity has taken us from seeing gender as operating only at an individual level, to viewing it as regime complete with 'rules, procedures, discourses and practices'; a regime in which, 'many men are comfortable and most women are not' (Lovenduski 2005, p. 147). In Connell's (2002, p. 7) view, this regime reflects the patterning of, and interaction between, four sets of gender relations including: the gender relations of power; the gender division of labour; the gender dimension of emotion and human relations and the gender dimension of culture and symbolism. Although analytically distinct, in practice these dimensions 'are found interwoven in actual relationships and transactions' (Connell 2002, p. 7). However, as Lovenduski's work suggests, it is important not to see gender power regimes operating alone. Gender intersects and combines with other structural power relations including race, sexuality and class to influence outcomes (see Weldon 2008).

Acknowledging the existence of a gender regime is important because it provides new insights into the power dimension of political institutions. It draws our attention to the asymmetry of institutional power relations (Kenny 2007, p. 96) and makes us look at how and what resources are distributed and who gets to do the distributing. Political systems have been constructed upon the exclusion or enforced absences of women and the feminine while ' $[\mathrm{t}]$ hat associated with males has received a disproportionate share of the resources and deemed more valuable than that which is associated with females' (Duerst-Lahti 2008, p. 182). This seems to be the case regardless of the nature of the political regime or culture. As gender and politics researchers have documented, a general pattern exists across all the regions of the world; in Latin America, Africa, Asia, the Middle East as well as in Europe, North America and Australia, entrenched gender stereotypes and control of political resources have worked to privilege (certain) men and disadvantage most women (see for example Chappell 2002, Molyneux and Razavi 2002, Waylen 2007, Tripp et al 2009, McBride and Mazur 2010). This relationship of 
advantage and disadvantage directly influences political and policy outcomes. In all parts of the world, women continue to earn on average less than men, have less control of capital, reduced rates of political representation, and suffer from (the lack of protection from) male violence (for details see United Nations Women 2011).

Masculine power advantage has been naturalized - seen as the way things should be - and 'has been capable of setting the terms of normal, just, and proper arrangements for political and social power' (Duerst-Lahti 2008, p. 165). This naturalization has not occurred through a conscious strategy on behalf of all men to dominate all women. As Hooper argues: 'men gain access to power and privilege not by virtue of their anatomy but through their cultural association with masculinity' (2001, p. 41). Nor has the naturalization of gender power relations come about through the exercise of brute force, but through a subtle accumulation of 'often-small advantages across a host of different institutional spaces' (Burns 2005, p. :138). Men's access to power has been reinforced over time through 'constantly repeated processes of exclusion' of women (Lovenduski 2005, p. 50), and through organizational rules, routines, policies and discourses that have rendered 'women, along with their needs and interests, invisible' (Acker 1992, p. 567; Hawkesworth 2005, p. 147).

Many women (and men who fall outside hegemonic boundaries, like homosexual men) have sought to disrupt these power relations by first identifying then challenging the gender foundations of taken-for-granted rules and practices within legislative, bureaucratic and legal arenas. For instance, feminist activists have drawn attention to and disrupted the gender dimensions of: recruitment practices of political parties which privileges favoured sons (Kenny 2011); the operation of discriminatory behaviour in legislatures to block women's access to leadership positions (Lovenduski 2005; Mackay 2008); the different career opportunities for men and women in the bureaucracy leaving the latter languishing in less important positions (Stivers 1993; Chappell 2002) and legal and constitutional arrangements which reinforce the public/private distinction in areas such as reproductive rights (Dobrowlosky and Hart 2003; Waylen 2007). However, gender norms have proven to be very 'sticky'. Challengers of existing gender logics of appropriateness have often been treated as 'deviants' and punished through acts of censure, ridicule or harassment. With the weight of history on their side, defenders of the gender status quo - those advantaged by existing power arrangements - have often defeated attempts to subvert the existing regime. The intersection between the gender regime and other structures of power further compound the challenge for those seeking change and improved outcomes.

But what these studies also reveal is that 'crisis tendencies' in gender regimes can emerge due to their inherent instability and internal contradictions also exist (Connell 1987, pp. 159-60). For example, the advancement of principles of universal rights, built on masculine foundations, opens up new discourses for furthering women's claims to citizenship, while changes in global capitalism challenge the traditional gender division of labour leading to the education and employment of more women in roles previously deemed male-only domains. These external and internal institutional pressures for change have not resulted in 'an automatic disruption of the institutional order of power' but they have made it increasingly vulnerable (Connell 1987, p. 160). What this suggests is that 
under certain conditions political institutions are not only gendered but they can be gendered; activists 'can work to instate practices and rules that recast the gendered nature of the political' (Beckwith 2005, pp. 132-3).

Understanding the formation and influence of the gender regime is a critical aspect of feminist political science and important to anyone interested in the operation of institutions. We argue that in order to understand this regime and why and how gendered rules, norms and practices change or stay the same, we need look within political organizations, to the operation of formal and the often invisible informal rules. By doing so, we are better able to explain why changes to formal rules do not always mean that institutions act in ways designers anticipated or wanted, as informal norms, rules and procedures are very powerful - particularly in terms of gender - and may undermine formal changes. For example in South Wales in the 1980s policy makers were surprised when levels of male unemployment did not fall as the newly-created jobs in the nascent electronics industries were not taken by redundant male steel workers as had been hoped but by women within those communities. Policy makers had misunderstood how the informal and yet rigidly entrenched rules and norms that comprise the institution of the sexual division of labour operated to ensure that certain jobs were seen as men's and others as women's jobs (Elson and Pearson 1989). We must therefore examine rules, norms and procedures in both their formal and informal incarnations, distinguishing between formal and informal and exploring the interplay between the two.

\section{GENDERING FORMAL AND INFORMAL INSTITUTIONS}

In order to understand this relationship between gender and formal and informal institutions, we must first explore how institutions are understood within NI. Despite the differences between the four (or more) variants of NI, they agree on the following. First, that institutions - whether understood ultimately as co-ordinating mechanisms that sustain or are moving to particular equilibria or created and maintained through cultural perceptions or path dependencies - constrain the behaviour of actors. As Ostrom argues institutions, 'operate to rule out some actions and to rule in others' (2005, p. 18 emphasis added). Moreover, these constraints arise from the interaction between formally codified rules and more informally understood conventions and norms (Peters 1999). As Hall and Taylor indicate, institutions range 'from the rules of a constitutional order or the standard operating procedures of a bureaucracy to the conventions governing trade union behaviour or bank-firm relations' (1996, p. 938). All institutionalists therefore share a belief that institutional forms are both formal and informal in nature. This position is reflected in North's widely used definition that an institution is 'any form of constraint that human beings devise to shape human interaction' (1990, p. 4). While initially NI analyses focused more on the formal rules of the game, exploring this distinction between the formal and the informal has become increasingly important and more sophisticated definitions of informal institutions are now emerging within this scholarship.

\section{Defining formal and informal institutions}

For all NIs, formal institutions are distinguished by codified rules (Lauth 2000, p. 24) that are 'consciously designed and clearly specified' (Lowndes 2005, p. 292). Formal 
institutions can vary in their form, from constitutions, statutes and bylaws, to individual contracts and operational guidelines (North 1990, p. 47). Formal institutions are often also delineated by the nature of their enforcement. Formal rules require methods to identify that a rule has been broken, ways to measure of the extent of the rule violation and mechanisms for punishing the violator (North 1990, p. 48). Formal institutions involve rules and procedures that are 'created, communicated, and enforced through channels widely accepted as official' (Helmke and Levitsky 2004, p. 727). It is this official enforcement, undertaken by a third party, which give an institution its legitimacy (Streek and Thelen 2005, pp. 10-11).

Defining informal institutions is more difficult. As Helmke and Levitsky note, the problem with this term is that it is treated as a residual category, and applied to 'virtually any behaviour that depart from...the written-down rules' (2004, p. 727). It is used in various ways in a range of different fields. In defining informal institutions, many authors emphasize their customary element (Casson et al 2010). They are understood to 'come from socially transmitted information and are part of the heritage that we call culture' (North 1990, p. 37), and are the 'traditions, customs, moral values, religious beliefs, and all other norms of behaviour that have passed the test of time' (Pejovich 1999, p. 166). Informal institutions are therefore often seen somewhat pejoratively as 'traditional' and counter-posed to 'modernity'. And for many, they lie primarily outside the formal institutions of the state. But for some development economists like Stiglitz (2000), informal institutions are seen more positively and elided with social capital. As with formal institutions, the means of enforcement of informal institutions is a distinguishing feature. Enforcement is often thought to operate not through third parties but through internal actors and self-enactment and self-assertion (Lauth 2000, p. 24).

Leading the field in comparative politics, Helmke and Levitsky $(2004 ; 2006)$ have provided a more tightly specified definition of particular use to political scientists. They agree that informal institutions are based on custom, but not exclusively. They include other practices, such as legislative norms and illicit behaviour by officials understood as having nothing to do with culture (2004, p. 727). Instead of conceiving informal institutions as evolving from widely held shared values, they stem from shared expectations (2004, p. 728). Moreover, while they agree that informal institutional enforcement does occur internally, they also argue that they can be enforced by outsiders, such as clan bosses and even by the state itself in cases of official corruption (2004, p. 727). Their definition of informal institutions, which incorporates these features, sees them as 'socially shared rules, usually unwritten, that are created, communicated, and enforced outside of officially sanctioned channels' (2004, p. 727). As political scientists, their interest is in informal political institutions operating within and impacting on the state and political arenas, rather than as distinct from formal institutions.

Helmke and Levitsky's definition brings a greater degree of precision to our understanding of what an informal institution is, but it does not necessarily make it any easier to trace them. Informal institutions, as Lauth (2000, p. 26) suggests, "shy away from publicity'. By their very nature, they are hidden and embedded in the everyday practices that disguised as standard, and taken-for-granted. Identifying the enforcement of 
informal institutions is also a challenge. Whereas the enforcement processes of formal institutions are relatively easily identified because they involve obvious actors such as police, courts, tribunals, and committees, sanctions for violating informal institutions take place through often 'subtle, hidden, and even illegal channels' (Helmke and Levitsky 2004, p. 733). Indeed Helmke and Levitsky (2006) argue that sanctions or enforcement measures may not even be evoked allowing some informal institutions to remain invisible. These features make informal institutions not only hard to identify but also particularly 'sticky' and resistant to change.

Formal and informal institutions may be analytically distinct but they exist in close relationship to each other (Grzymala-Busse 2010; Azari and Smith 2012). For some, the formal is an outgrowth or crystallization of the informal, existing on a continuum from taboos and customs through to written constitutions (North, 1990, p. 46). As Olsen explains, 'evolving behavioural patterns' are 'frozen' into habits and traditions, and formally codified' $(2009$, p. 6$)$. In these interpretations, the informal precedes the formal. Others treat the relationship as less linear and more layered and overlapping. Ostrom's notion of 'rules-in-use' (as opposed to 'rules-in-form') (2005), and applied in the work of Lowndes (2005), suggests formal and informal rules interact and co-exist to 'guide and constrain political behaviour' (Lowndes et al 2006, p. 546). For Helmke and Levitsky, informal institutions emerge in relation to formal rules and operate in constant interaction alongside them. Informal institutions arise for a number of reasons: because formal institutions are incomplete; it is too difficult to change formal institutions so the informal becomes 'a second best strategy'; or to allow actors to pursue goals not publicly acceptable including unpopular or illegal activities (2004,p. 730).

As a result Helmke and Levitsky (2006, p. 3) argue, with reference to the impact of informal institutions on political institutions in Latin America, that there are 'myriad, complex and often unexpected effects: whereas some informal rules compete with and subvert democratic institutions, others complement and even help sustain them'. They cite the positive role that informal institutions can play in mitigating some of the undesirable aspects of multi-party presidentialism. Therefore, as a number of scholars have recently noted, the informal can work to undermine, replace, support or work in parallel with the formal institutions of the state (Grzymala-Busse 2010; Radnitz 2011; Azari and Smith 2012).

Any understanding of the hidden life of institutions therefore must begin with the formal and informal rules, norms and practices that comprise institutions. Understanding the interaction between the formal and informal dimensions is crucial - not only for investigating how far informal institutions, such as particularism or 'traditional' institutions are competing with or subverting formal rules, or even substituting for them, as has been the case for much research in the developing world, but also examining the extent to which informal norms play an important complementary role to formal rules as in much of the research on the developed world (Helmke and Levitsky 2006, p. 12).

\section{Gender and formal and informal rules}

With this background in mind, what does the primacy of rules, norms and practices and the formal/informal distinction mean for a gendered understanding of institutions? And 
what does a gender approach to institutions bring to an understanding of the relationship between these sets of rules? As Lowndes and Roberts (2013) suggest there are many dimensions to this. First, we can think about different ways that rules are gendered. There are identifiable rules about gender - these may be formal or informal and they shape how male and female actors behave. Rules - whether formal or informal also have gendered effects - largely because of their interaction with other rule sets. For instance, seemingly 'neutral' formal rules about the timing of meetings have gendered effects because of informal rules about women's caring responsibilities. And the actors who work with rules - whether as rule-makers, breakers and shapers - are also gendered. They embody various constructions of masculinity and femininity that impact on the ways in which they create, interpret, communicate, enforce, shape and comply with rules (Lowndes and Roberts 2013).

Space does not permit us to explore each of these three dimensions of gender and institutions, but looking more closely at the first category, rules about gender, provides some indication of how formal and informal rules operate to influence institutional outcomes. It is relatively easy to identify where formal gender rules have been enforced through officially accepted channels, and in ways that intentionally or inadvertently discriminate against women. Expectations about men's and women's responsibilities, capacities, duties and behaviour have been encoded into formal institutions in ways that limit women's voting rights, military service, remuneration, and employment service and conditions. A good example relates to the operation of the 'marriage bar' for women in the civil service in many countries after World War II. Aside from forcing many women out of (or refusing them entry into) the bureaucracy, these rules kept women within state agencies in junior, sex-segregated posts, prevented their promotion and interfered with their capacity to accrue pensions. These rules influenced the broader culture and attitude of the civil service, including the view that women were capable of tea-making, typing and little else. It also suggested that men should be the main bread-winners, that they were entitled to career opportunities and that their work commitments would be supported by a full-time wife. Challenges to formally encoded gendered rules like these have been met with official sanctions and punishment for violating the rules. In the case of the marriage bar, women who were discovered attempting to keep their marriages secret were sacked from the civil service; a salutary lesson for others seeking to do the same.

However, over time, changes in the operation of formal rules have also occurred with gendered implications, both intended and not. Returning to the marriage bar example, new formal rules explicitly designed to promote gender equality and prevent gender discrimination in employment in civil service positions were widely introduced in western liberal states throughout the 1970s and 80s. These changes came about in part because actors seeking to change the rules had access to a third party - in the form of a court, legislature or bureaucratic policy-making machinery - which allowed for adjudication of these rules. This adjudication combined with broader cultural shifts helped produce a 'crisis' (in Connell's sense) of the gender order and an opportunity to challenge and overturn the official preference for the employment of male civil servants.

Reforming these formal rules may have ended officially sanctioned gender 
discrimination, but it did not overcome all institutionalized forms of male bias. This is because informal institutions and gender norms, and the hierarchical relations in which they exist, are not 'wiped out' by changes in formal rules. While gender norms may be decoupled from formal institutions, like the removal of the marriage bar and the introduction of equal employment opportunity policies, earlier rules about gender can survive in an informal guise and continue to operate to enforce the same (old) expectations, relationships and power structures. So where formal rules have been reformed, informal ones can continue to operate to contradict them. In Australia, ten years after the removal of the marriage bar a public servant gave evidence to a Royal Commission on the Public Service that until the age of 28 women in clerical roles were more efficient than men, but that "unmarried women over that age became inefficient, unhappy or disruptive...married women employees are more interested in their homes than their careers and voluntarily accept restricted promotion opportunities" (Tapperell et al 1976). Over forty years after the marriage bar was removed from Australian public service, women still make up the majority of part-time staff (29 per cent women compared with 4 per cent men) and men hold just under two thirds of the senior executive positions (EOWA 2011). Moreover, expectations about the type of person who should lead a public sector agency continue to reflect masculine traits that are seen as unsuitable for women to display (Chappell 2002). In this case informal institutions have served to subvert and substitute for the new formal rules; here informal institutions are certainly not complimentary, nor do they act to reinforce the new formal rules.

The examples given so far suggest that formal and informal gender norms only work in one direction; to disadvantage women and advantage men. However, this is not necessarily the case. While gender norms may work with or against formal institutions to entrench gender inequalities, they can also potentially destabilize male bias (Banazsak and Weldon 2011). This 'regendering' (Beckwith 2005) process may offer new political possibilities for those disadvantaged by earlier institutional arrangements. For instance, recent work on strategies to address violence against women shows that norms can be created, in this case around state obligation to address this issue, and harnessed to advance a gender equality agenda (Weldon 2002; Franceschet 2011, p. 67). Moreover, greater attention to work/life balance has led to some states introducing parental leave arrangements to make it easier for some men to play a role in childcare. For this process to work, 'positive' changes in formal rules must be accompanied by complimentary changes in informal rules and norms that serve to bolster formal rule change. As is clear from this discussion, formal institutions, informal institutions and gender norms are interdependent. As Banazsak and Weldon argue, 'gender equality outcomes cannot be read off either informal or formal institutions examined alone', but it is the interaction between them that shapes these outcomes (2011, p. 270).

The outcomes of interactions between the gendered formal and informal rules and norms are complex and must be understood through in-depth context specific analysis. Each political arena operates according to its own gendered 'logic of appropriateness'. Legislatures, executives, the bureaucracy and legal and constitutional arenas include their own sets of formal rules that are propped up or undermined by informal rules, norms and practices, including those explicitly related to gender as well as those that are implicitly 
gendered. This discussion suggests that there are hidden rules within institutions that need to be placed at the forefront of institutional research to understand institutional evolution and change. NI scholars need to pay attention to the gender dimensions of both formal and informal institutions, and FI researchers need to focus on the informal as well as formal aspects of institutions. Exploring how to carry out such research is the focus of the next section.

\section{UNCOVERING THE HIDDEN LIFE OF INSTITUTIONS}

We can use the ideas and concepts discussed in the previous sections to research the hidden life of institutions, helping us to understand not only how both formal and the informal rules, norms and practices are gendered, but also how they and the interaction between then can contribute to processes of change. As this research is still in its infancy, in this section we focus on some of the strategies, approaches and methods that can be used. We examine one limited case study - the UK core executive and in particular recruitment to the top civil service - that might help us improve our analyses of the executive and bureaucratic arenas. We use existing research to develop a gendered analysis; suggest further work that could enhance both FI and NI understandings of the core executive and demonstrate the wider applicability of this kind of approach.

There are a number of ways we can investigate formal and informal institutions in terms of rules, norms and practices and the relationship between them. Exploring the nature of formal institutions and the rules that constitute them is somewhat easier. Official documentation, published and unpublished reports on structures and processes as well as interviews with key actors can all help to determine both formal rules about gender, the gendered implications of the formal rules and the rule makers and breakers.

Uncovering informal institutions and unraveling their relationship to the formal is more difficult and challenging. How do we recognise, uncover and analyse the informal? It requires more systematic in-depth detailed and often ethnographically-based work (Radnitz 2011, pp. 365-6). This used to be relatively rare in political science, despite its use in other social sciences, such as institutional ethnography (Smith 2005). But more research of this kind, much of it from an interpretive perspective, has been undertaken within political science and in public administration - exemplified by the recent work of Rhodes (2011) and Bevir and Rhodes $(2006 ; 2008 ; 2010)$. However although it delivers some fascinating and innovative insights about the hidden life of institutions, it has not been undertaken in specifically gendered ways, or used a gendered lens.

Not withstanding its undoubted usefulness, as Feminist Institutionalists, we also concur with others that there are a number of problems with it (see MacAnulla 2006; Smith 2008; Glynos and Howarth 2008; Marsh 2008; Richards 2008; Hay 2011; and Gains 2011). Despite its advocacy of 'situated agency', a danger of an interpretive approach is that it gives too much primacy to actors, their practices and beliefs, to the exclusion of the institutional context in which they operate. This context both constrains and facilitates actions in important ways that do not and cannot figure in the interpretive analyses. This can result in an almost pluralist account that underplays power differentials, structures and hierarchies - including those operating around gender seeing class, race and gender as simply 'particular clusters of similarities and differences' 
(Bevir and Rhodes, 2008:731). Finally despite their emphasis on examining the actions and beliefs of elite actors, interpretive scholars like Rhodes spend little time considering their own beliefs, subjectivities and subject positions and how these may impact on the research process - affecting for example what they consider to be noteworthy and significant. They still fall back on notions of 'objectivity' even if these differ from standard definitions as they are based on what they call 'intersubjective agreement' (Rhodes, t'Hart and Noordegraaf 2007, p. 11; Bevir and Rhodes 2010, p. 207).

Research exploring informal institutions is therefore constrained by particular methodological challenges. Although we must be attentive to structure as well as actors, the research methods appropriate for investigating the informal are ones likely to privilege actors, their actions and views about themselves. As in-depth interviews, ethnography and participant observation are important ways to get at formal versus informal rules and how these work together and against each other, we need to be aware of their potential pitfalls. There are practical issues around openness and confidentiality. It is likely that many interviewees and research subjects will be distinguishable if there are only a small number of women in the potential pool. For example between 1945 1997 there were only five female Permanent Secretaries (PS) in British civil service and therefore any details of their position, career trajectory or family life was likely to make them easily identifiable. Additionally actors within these institutions may not even perceive the existence of informal rules because these are so normalized and taken-forgranted as to render them invisible (a problem for all interpretive accounts). One senior female PS interviewed in the late 1990s argued that many senior women civil servants did not recognize questions of gender as relevant to them or even possess the language or concepts that would enable them to do so. Finally actors may feel that it is not in their interests to publicly recognize gender as an issue. Indeed, even if they did not engage with these issues in an interview, they would sometimes do so privately. Evidence, again from the 1990s, would suggest that senior women interviewees who denied that their gender had been an issue in the civil service sometimes said very different things in the non-interview context. ${ }^{1}$ Ethnographic work, therefore while central, can only be one strategy amongst many. Research findings have to be triangulated with other forms of data, for example with policy documents, rule books and reports, to help to maintain a balance between actors and their institutional context.

One way of illustrating the arguments we have made thus far is to look more systematically at some of the existing research on the core executive. The now vast mainstream literature on this topic, much of it UK based, includes a substantial amount of scholarship examining the 'informal rules of game', but rarely within an institutionalist framework. It also does not use an overtly gendered perspective. David Richards and Martin Smith $(2000 ; 2004)$, for example, utilized a critical realist approach to examine notions dominant within the UK civil service such as the 'public service ethos' and political neutrality, arguing that although they are presented as fundamentally

1 Interview and other data from two ESRC funded projects: primarily 'The Changing Role of Central Government Departments' (L124251023) conducted between 1995-8 by D. Marsh, D. Richards and M.J. Smith, but also 'Labour and the Reform of Whitehall: Inheritance, Transition and Accommodation' (R000222657) conducted between 1998-2000 by D. Richards and M.J. Smith. 
normatively good, they actually legitimate the rule of a power elite. Indeed the generally harmonious relations between ministers and civil servants stem in part from a shared belief in the 'Westminster model' and often shared backgrounds in terms of race, class and gender. But, despite their acknowledgement of the existence of asymmetric power and structured inequalities that includes gender, Richards and Smith do not explicitly analyse gender as an important component of these ideas and processes (as demonstrated for example by analyses of how norms of neutrality are gendered or recognize the existence of a particular gender regime) (Chappell 2002). However this body of nongendered work provides us with important insights.

As the same time, the majority of the gender and politics scholarship to date has largely ignored the executive and core executive in favour of researching the legislature, levels of women's representation and quotas. Some work on gender and the executive has now begun (Jalalzai 2008). But much of it simply counts the numbers of women in executives. However Claire Annesley and Francesca Gains (2010) have explored what they call the 'gendered disposition' of the UK core executive. Based on interviews with participants as well as published sources and documents, they examine how recruitment, power resources, informal norms and practices in governing operate in gendered ways. In particular Annesley and Gains (2010) examine the efforts of two 'feminist' New Labour ministers who were happy to be interviewed and identified, focusing on their attempts to introduce gender equality policies from their ministerial bases in the Departments of Trade and Industry and Social Security.

Although an important start, more needs to be done to develop a coherent FI approach to the core executive. We must broaden out from the existing research on the feminist ministers and gender equality policies to explore how the core executive is gendered more generally. The task is therefore to go beyond this somewhat vague notion of a 'gendered disposition' to systematically examine the gendered nature of the core executive in both formal and informal terms - looking for example at how the different departments such as health, finance or defence work - delineating the formal and informal rules that operate on a day to day basis, and how these impact on a range of outcomes, not just gender equality ones. It will then be possible to look at change over time and undertake more comparative analyses.

The primary data necessary to undertake these tasks have not yet been collected, but by utilizing the existing research, we can examine one under-explored aspect of the gendered operation of formal and informal institutions - namely recruitment to and promotion within the upper echelons of the British civil service - as a key element of the core executive (for an early exception to this lacuna see Watson 1994). The higher echelons have remained male dominated (as well as exclusionary in terms of race and class) despite a series of formal initiatives and more informal understandings that should have challenged this more extensively (Lowe 2011). First, the formal rules on gender changed in the 1970s as the 1970 Equal Pay Act and the 1975 Sex Discrimination Act removed the general prohibitions on the employment of women. At the same time internal civil service reports like the 1971 Kemp Jones Report on the employment of women in the civil service and the 1981 report on equal opportunities for women in the civil service outlined the problems within the sector; and finally the civil service was 
always considered to be a 'good' employer of women. However little changed between 1968 and 1981 when all the permanent secretaries were still male. Women comprised only $2.5 \%$ of deputy secretaries in both 1968 and 1981; and only at the level of Under Secretary could any change be seen as the percentage of women had increased from $2.4 \%$ to $4.4 \%$ (Lowe 2011, p. 330). These proportions have grown in recent years. In 1995 there were still only two female Permanent Secretaries (PS) and in January 2011 only eight of the 42 Permanent Secretaries were women. However by December 2011 this figure had increased to thirteen. The research that has already been conducted can help us to unpack these figures and provide insights into the informal institutional norms and practices that contributed to the continued male dominance, despite both the official rhetoric and formal initiatives introduced to reduce male dominance at the top. And perhaps also help us to explain the recent increase in numbers.

In the face of formal institutional equality, male and female career trajectories remained guided by the continued existence of these informal norms and practices. The route to permanent secretary has long been to work in a minister's private office as a private secretary and this typically happens when a civil servant is in their late 20 s and 30s (Rhodes 2011). This is a very demanding job and requires the civil servant to be always available for the minister working seven days a week if necessary, at a time when many women will have caring responsibilities that would conflict with this long hours culture; and Lowe argues that this informal norm may hinder their career progression (Lowe 2011). Robin Butler, who became a private secretary in the Treasury in 1964 aged 26 and ended his career in 1998 as Cabinet Secretary, admitted that he never saw his children in their school uniforms as he left home before they were dressed in the morning and never returned before they were asleep in the evening (Interview, The Secret Life of Whitehall: The Private Office, BBC4, 30 March 2011). Indeed one senior female official interviewed in the late 1990s argued that not having children had definitely made her career progression easier. And as late as the mid 1990s, high-flying women civil servants were often still referred to as 'good chappesses'.

Even when women have progressed successfully, they are more likely to reach the top in certain departments and positions. In the late 1990s a senior female official in the then Department of Social Security DSS claimed that although women could become deputy secretary in the Treasury, it was accepted that they would not be promoted to Permanent Secretary. ${ }^{3}$ Senior women therefore had to exit the Treasury and usually into the 'social side' to advance, even though a more accepted and 'normal' career path was to stay for long periods and be promoted within the same department. This pattern of women PSs predominating in certain departments, often the 'softer' welfare orientated ones (mirroring the appointments that women ministers often get) as well as agencies, has remained despite the increased number of women. Although in December 2011 there was one female PS (of four) in Defence, women were clustered in Health, Work and Pensions, and Customs and Excise, while men still dominated in the Cabinet Office (seven out of seven) and the Treasury.

It is important to develop this earlier research on women's career trajectories and

\footnotetext{
${ }^{2}$ Interview data from research cited in footnote 2 .

${ }^{3}$ Interview data from research cited in footnote 2 .
} 
bring it up to date. We need to ascertain how far the informal norms and practices commonplace up to the late 1990s remain and how far they have changed. Is the recent rash of appointments of female PSs a significant development? It would be useful to interview the female and male civil servants who participated in research in the 1990s specifically about how they saw gender operating. It is also necessary to talk to current civil servants, both male and female, to see if their backgrounds, perceptions and career progression are different either to earlier women civil servants or to their contemporaries of the opposite sex. Do women civil servants exhibit any significant differences to their male colleagues in terms of race and class, namely white and upper/middle class? Do private school and Oxbridge backgrounds also predominate amongst the women? Evidence from informal interviews suggests that they might. ${ }^{4}$

It would also be useful to look at the broader institutional changes that have taken place since the mid 1990s and their relationship to the gendering of rules, norms and practices. One often remarked upon, but as yet relatively un-researched, development is the rise of Special Advisers (SpAds) who have been increasingly formally incorporated into the core executive through codes of conduct and legislation (Gains and Stoker 2011). Again anecdotal evidence suggests that SpAds are similar in background to the career civil servants - predominantly male, white and middle class - except they are often younger as a period spent as a SpAd is frequently a precursor to a career in electoral politics. Male SpAds appear more prevalent at the centre of government - for example in the Prime Minister's office, the Treasury and Cabinet Offices - than at the margins (although some female New Labour ministers, including those researched by Annesley and Gains, deliberately employed female SpAds). This needs further investigation as does the increased recruitment of those without a career civil service background. It would improve our understanding of both long-standing informal norms and practices and the emergence of any new ones around career progression and appropriate positions for men and women in the core executive. Ultimately this research could be extended to examine the impact that the potentially different gender norms present in a range of departments may have on the institutional cultures and on outcomes. It could, for example, compare the 'hard' central departments such as the Treasury with 'softer' spending ones such as Department of Health and Social Security.

\section{CONCLUSIONS}

All institutions are profoundly imbued with gender. This is not always perceived but has important consequences that are both intended and unintended. The operation of gendered rules, norms and practices (and their intersection with race, class and sexuality structures) influences institutional design choices and processes. As the case of the core executive highlights, it also shapes institutional outcomes. The advantage of adopting a gender and institutions approach is that it allows NIs to better explain the origins, enforcement and outcomes of institutions, and helps feminist scholars understand why even the most well designed formal gender equality rules, such as efforts to increase the number of women in the public sector, often fail to produce their intended effects.

We have argued that to be able to understand how these processes occur and are

4 Informal interviews with an ex Labour SpAd and a Treasury civil servant, November 2011. 
reinforced, it is necessary not only look to formal rules, but also to look at their more hidden aspects, to informal institutions. This involves identifying unspoken and accepted norms that may guide decision-making - exposing and questioning the gender status quo or 'logic of appropriateness'. Identifying the hidden life of institutions presents challenges for researchers. Here we have demonstrated preliminary ways in which these can be overcome, building for example on some of the existing research on the core executive to examine how recruitment and progression in one part of the UK core executive has been affected by gendered informal rules, norms and practices. We have also suggested some ways in which this research could be extended to help to understand how far these informal institutions have remained in place or been modified.

This research agenda can be broadened further still. Paying attention to informal gender institutions can contribute to the emerging focus in NI scholarship on institutional change and in gender research on reforming political institutions to advance equality. The argument presented here suggests that in order to understand change researchers cannot only focus on change within formal institutions, as this will provide just a partial piece of the puzzle. Any effort to understand institutional change must be complemented by attention to the informal institutions that exist in any particular context and their gender dimensions, as well as specific considerations about how these rules and norms can be unraveled and dismantled.

Another important direction for future research on the hidden life of institutions is to chart in more detail the intersection between different power structures. We have highlighted in this paper the existence of a gender regime, but as we have also noted, this operates within a context that is also imbued with other informal institutions that exist along race, class, sexuality and other axes. By paying more attention to how and where these various power structures operate, interact and the force they exert, will improve our understanding of the complexities of institutional design, continuity and change. Again it should also help us better explain why changes in formal rules do not always have the effect institutional designers intended.

Institutions are complex. They have formal and informal dimensions. Finding the more hidden aspects of institutions present challenges for researchers, but as we have argued, they are not insurmountable. Difficult or not, it is essential to pursue this research direction in order to provide a more nuanced and realistic account of institutions, their design, operation and effects and to better understand how to reform them to produce more equal outcomes for all.

\section{ACKNOWLEDGEMENTS}

We would like to thank the participants of the 2010 Sydney workshop on Rethinking the Dynamics of Political Institutions for giving us the inspiration for this article, and especially to Fiona Mackay for her critical and encouraging comments throughout its development. We would also like to thank Vivien Lowndes, Dave Richards and Patrick Diamond for all their help and advice. Louise would also like to acknowledge the support of the Australian Research Council Discovery Project 
funding (DP0879958) that supported her contribution to the article.

\section{REFERENCES}

Acker, J. 1992. 'From Sex Roles to Gendered Institutions', Contemporary Sociology, 21, $5,565-69$.

Annesley, C. and F. Gains. 2010. 'The Core Executive: Gender Power and Change', Political Studies, 58, 5, 909-929.

Azari J. and J. Smith. 2012. 'Unwritten Rules: Informal Institutions in Established Democracies', Perspectives on Politics, 10, 1, 37-55.

Banazsak, L.A and S.L. Weldon. 2011. 'Informal Institutions, Protest, and Change in Gendered Federal Systems', Politics \& Gender, 7, 2, 262-273.

Beckwith, K. 2005. 'A Common Language of Gender?', Politics and Gender, 1, 1, 128 37.

Beckwith, K. 2010. 'Introduction: Comparative Politics and the Logics of a Comparative Politics of Gender', Perspectives on Politics, 8, 1, 159-168.

Bevir, M. and R. Rhodes. 2006. Governance Stories. Abingdon: Routledge.

Bevir, M. and R. Rhodes. 2008. 'The Differentiated Polity as Narrative', British Journal of Politics and International Relations, 10, 4, 729-734.

Bevir, M. and R. Rhodes. 2010. The State as Cultural Practice. Oxford: Oxford University Press.

Burns, Nancy. 2005. 'Finding Gender', Politics \& Gender, 1,1, 137-141.

Casson, M.C., M. Della Giusta and U.S. Kambhampati. 2010. 'Formal and Informal Institutions and Development', World Development 38, 2, 137-141.

Chappell, L. 2002. Gendering Government: Feminist Engagement with the State in Australia and Canada. Vancouver: University of British Columbia Press.

Chappell, L. 2006. 'Comparing Institutions: Revealing the "Gendered Logic of Appropriateness"', Politics \& Gender, 2, 2, 223-235.

Connell, R.W. 1987. Gender \& Power. Cambridge: Polity Press.

Connell, R.W. 2002. Gender. Cambridge: Polity Press.

Dobrowolsky, A. and V. Hart (eds). 2003. Women Making Constitutions. Basingstoke: Palgrave.

Durest-Lahti, G. 2008. 'Gender Ideology: Masculinism and Feminalism', in G. Goertz and A. Mazur (eds), Politics, Gender, and Concepts: Theory and Methodology. Cambridge: Cambridge University Press, pp. 159-192.

Elson, D. and R. Pearson (eds). 1989. Women's Employment and Multinationals in Europe. London: Macmillan.

Equality for Women in the Workplace Australia (EOWA). 2011. Women's Representation in the Public Sector. Canberra: Australian Government. Available from: www.ewoa.gov.au (accessed 17 November 2011).

Franceschet, S. 2011. "Gendered Institutions and Women's Substantive Representation: Female Legislators in Chile and Argentina." In M.L. Krook and F. Mackay (eds), Gender, Politics, and Institutions: Towards a Feminist Institutionalism. London: Palgrave Macmillan. pp. 58-78, 2011.

Gains, F. 2011. 'Elite Ethnographies: Potential, Pitfalls and Prospects for Getting “Up 
Close and Personal"', Public Administration, 89, 1, 156-66.

Gains, F. and G. Stoker. 2011. 'Special Advisers and the Transmission of Ideas from the Policy Primeval Soup', Policy and Politics, 39, 4, 485-98.

Glynos, J. and D. Howarth. 2008. 'Structure, Agency and Power in Political Analysis: Beyond Contextualised Self-Interpretations', Political Studies Review, 6, 2, 155-69.

Goetz, A.M. 2007. 'Gender Justice, Citizenship and Entitlements: Core Concepts, Central Debates and New Directions for Research', in M. Mukhopadhyay \& N. Singh (eds), Gender Justice, Citizenship and Development. Ottawa: Zubaan /International Development Research Centre, pp. 16-57.

Grzymala-Busse, A. 2010. 'The Best Laid Plans: The Impact of Informal Rules on Formal Institutions in Transitional Regimes', Studies in Comparative International Development, 45, 3, 311-33.

Hall, P. and R. Taylor. 1996 'Political Science and the Three New Institutionalisms', Political Studies, 46, 5, 951-957.

Hawkesworth, M. 2005. 'Engendering Political Science: An Immodest Proposal', Politics and Gender, 1, 1, 141-156.

Hay, C. 2011. 'Interpreting Interpretivism, Interpreting Interpretations: The New Hermaneutics of Public Administration', Public Administration, 89, 1, 167-82.

Helmke, G. and S. Levitsky. 2004. 'Informal Institutions and Comparative Politics: A Research Agenda', Perspectives on Politics, 2, 4, 725-740.

Helmke, G. and S. Levitsky. 2006. 'Introduction', in G. Helmke and S. Levistsky (eds), Informal Institutions and Democracy: Lessons from Latin America. Baltimore: Johns Hopkins University Press, pp. 1-32.

Hooper, C. 2001. Manly States: Masculinities, International Relations and Gender Politics. New York: Columbia University Press.

Jalalzai, F. 2008. 'Women Rule', Politics and Gender, 4, 3, 205-31.

Kenny, M. 2007. 'Gender, Institutions and Power: A Critical Review', Politics, 27, 91-100.

Krook, M.L. and F. Mackay (eds). 2011. Gender, Politics and Institutions: Towards a Feminist Institutionalism. Basingstoke: Palgrave.

Krook, M. L. and F. Mackay. 2011. 'Introduction: Gender, Politics, and Institutions', in M. L. Krook and F. Mackay (eds), Gender, Politics and Institutions: Towards a Feminist Institutionalism. Basingstoke: Palgrave, pp. 1-20.

Lauth, H-J. 2000. 'Informal Institutions and Democracy', Democratization, 7, 4, 21-50.

Lovenduski, J. 2005. Feminizing Politics. Cambridge: Polity Press.

Lowe, R. 2011. The Official History the Civil Service, Basingstoke: Routledge.

Lowndes, V. 2005. 'Something Old, Something New, Something Borrowed...How Institutions Change (and Stay the Same) in Local Governance', Policy Studies, 26, 3, 291-309.

Lowndes, V., L. Pratchett and G. Stoker. 2006. 'Local Political Participation: The Impact of Rules-in-Use', Public Administration, 84, 3, 539-561.

Lowndes, V. and M. Roberts. 2013. Why Institutions Matter. Basingstoke: Palgrave.

Mackay, F. 2008. '"Thick" Conceptions of Substantive Representation: Women, Gender and Political Institutions', Representation, 44, 2, 125-139.

Mackay, F. and G. Waylen. 2009. 'Critical Perspectives on Feminist Institutionalism', 
Politics \& Gender, 5, 2, 237-280.

Mackay, F., M. Kenny and L. Chappell. 2010. 'New Institutionalism Through a Gender Lens: Towards a Feminist Institutionalism?', International Political Science Review, 31, 5, 1-16.

MacAnulla, S. 2006. 'Challenging the New Interpretist Approach: Towards A Critical Realist Alternative', British Politics, 1, 1:113-38.

Mahoney, J. and K. Thelen (eds). 2010. Explaining Institutional Change: Ambiguity, Agency, and Power. Cambridge: Cambridge University Press.

March, J.G. and J.P. Olsen. 1984. 'The New Institutionalism: Organizational Factors in Political Life', The American Political Science Review, 78, 2, 734-749.

Marsh, D. 2008. 'Understanding British Government: Analysing Competing Models', British Journal of Politics and International Relations, 18, 2, 251-68.

McBride, D. and A. Mazur. 2010. The Politics of State Feminism. Philadelphia: Temple University Press.

Molyneux, M. and S. Razavi. 2002. Gender Justice, Development and Rights. Oxford: Oxford University Press.

North, D. 1990. Institutions, Institutional Change and Economic Performance. Cambridge: Cambridge University Press.

Olsen, J. 2009. 'Change and Continuity: An Institutional Approach to Institutions of Democratic Government', European Political Science Review, 1, 1, 3-32.

Ostrom, E. 2005. Understanding Institutional Diversity. Princeton: Princeton University Press.

Pejovich, S. 1999. 'The Effects of the International of Formal and Informal Institutions on Social Stability and Economic Development', Journal of Markets and Morality, 2, 2, 164-81.

Peters, B.G. 1999. Institutional Theory in Political Science: The 'New Institutionalism'. London: Pinter.

Radnitz, S. 2011. 'Informal Politics and the State', Comparative Politics, 43, 3, 351-71.

Rhodes, R.A.W. 2011. Everyday Life in British Government. Oxford: Oxford University Press.

Rhodes, R.A.W., S.A. Binder and B.A. Rockman (eds). 2006. The Oxford Handbook of Political Institutions. Oxford: Oxford University Press.

Rhodes, R.A.W., P. 't Hart, and M. Noordegraaf. 2007. 'Being There', in R.A.W. Rhodes, P. 't Hart, and M. Noordegraaf (eds), Observing Government Elites: Close Up and Personal. Basingstoke: Palgrave, pp. 1-17.

Richards, D. 2008. New Labour and the Civil Service: Reconstituting the Westminster Model. Basingstoke: Palgrave.

Richards, D. and M. Smith. 2000. 'The Public Service Ethos and the role of the British Civil Service', West European Politics, 23, 3, 45-66.

Richards, D. and M. Smith. 2004. 'Interpreting the World of Political Elites', Public Administration, 82, 4, 777-800.

Schmidt, V. 2008. 'Discursive Institutionalism: The Explanatory Power of Ideas and Discourse', Annual Review of Political Science, 11, 303-26.

Smith, D. 2005. Institutional Ethnography: A Sociology for the People. Rowman: 
Altamira.

Smith, M. J. 2008. 'Re-Centring British Government: Beliefs, Traditions and Dilemmas in Political Science', Political Studies Review, 6, 2, 143-54.

Stiglitz, J .2000. 'Formal and Informal Institutions', in P. Dasgupta and I. Serageldin (eds), Social Capital: A Multi-faceted Perspective. Washington D.C.: World Bank.

Stivers, C. 1993. Gender Images in Public Administration: Legitimacy and the Administrative State. Newbury Park: Sage.

Streek, W. and K. Thelen. 2005. 'Introduction', in W. Streeck and K. Thelen (eds), Beyond Continuity: Institutional Change in Advanced Political Economies. Oxford: Oxford University Press, pp. 1-39.

Taperell, K., C. Fox, and M. Roberts. 1976. Sexism in Public Service: The Employment of Women in Australian Government Administration, Discussion Paper 3. Canberra: Royal Commission on Australian Government Administration.

Thelen, K. 2009. 'Institutional Change in Advanced Political Economies', British Journal of Industrial Relations, 47, 3.

Tripp. A., I. Casimiro, J. Kwesiga, and A. Mungwa. 2009. African Women's Movements: Changing Political Landscapes. Cambridge: Cambridge University Press.

United Nations (UN) Women. 2011. Progress of the World's Women: Women, War, Peace. New York: UN Women.

Watson, S. 1994. 'Producing the Right Sort of Chap', Policy and Politics, 22, 3, 211-22.

Waylen, G. 2007. Engendering Transitions: Women's Mobilization, Institutions and Gender Outcomes. Oxford: Oxford University Press.

Weldon, S. L. 2002. Protest, Policy and the Problem of Violence Against Women; A Cross-national Comparison. Pittsburgh: University of Pittsburgh Press.

Witz, A. and M. Savage. 1992. 'Theoretical Introduction: Gender in Organizations', in M. Savage and A. Witz (eds), Gender and Bureaucracy. Oxford: Blackwell. 